\title{
Mobile Learning: Explorando as possibilidades do App Inventor para a criação de objeto educacional móvel
}

\author{
Priscila Cadorin Nicolete ${ }^{1}$, Liane Margarida Rockenbach Tarouco ${ }^{1}$, Aline Coêlho \\ dos Santos ${ }^{2}$ \\ ${ }^{1}$ Pós-Graduação em Informática na Educação - Universidade Federal do Rio Grande do \\ Sul (UFRGS). Av Paulo Gama 110, Anexo III, 344 - Porto Alegre (RS) Brasil \\ ${ }^{2}$ Ensino Médio Conecte - Serviço Nacional de Aprendizagem Industrial (SENAI). Av. 1 \\ de Maio 670 - Primeiro de Maio, Brusque (SC) Brasil \\ priscilanicolete@hotmail.com, lianedpenta.ufrgs.br, \\ aline.c@edu.sc.senai.br
}

\begin{abstract}
This work presents a proposal for a digital learning object, developed through the MIT App Inventor platform, in order to explore the possibilities of the platform and verify its potential for teachers to create their own applications for pedagogical use in the classroom.
\end{abstract}

Resumo. Este trabalho apresenta uma proposta de objeto digital de aprendizagem, desenvolvido por meio da plataforma MIT App Inventor, com objetivo de explorar as possibilidades da plataforma e verificar sua potencialidade para professores criarem seus próprios aplicativos para o uso pedagógico na sala de aula.

\section{Introdução}

Estudos tem mostrado que a Mobile Learning tem potencial para se tornar uma parte integral dos processos de ensino e de aprendizagem, pois é cada vez mais comum os alunos e professores terem e usarem tecnologias móveis. Estes dispositivos são aparelhos digitais, com hardwares potentes e preços acessíveis, facilmente portáteis, de fácil interação e com acesso à internet, que executa um amplo número de ações, inclusive multimídias (Unesco, 2014). Isso faz desses dispositivos portas para o ensino e aprendizagem, colaboração e produtividade contínua, estimuladas pela Internet. (Hofmann, 2006).

Diante desse cenário, o estudo apresenta o planejamento e a construção de um aplicativo educacional móvel para o ensino da teoria "Princípio de Arquimedes". O objeto de aprendizagem foi inspirado no experimento desenvolvido por Piaget e Inhelder que se encontra no livro "Da lógica da criança a lógica do adolescente". Os autores elaboraram um experimento do qual um sujeito, diante de alguns objetos, deve classificálos de acordo com o fato de flutuarem ou não na água, depois, para cada objeto, deve indicar as razões de sua classificação, a seguir, o sujeito faz a experiência colocando os objetos na água. Ao final deve resumir seus resultados a fim de chegar a uma lei (Piaget \& Inhelder, 1976).

Os estudos de Piaget e colaboradores não tinham como objetivo a construção do conhecimento escolar, mas o processo de desenvolvimento cognitivo (Nogueira \& Rezende, 2014). Diante disso, o objeto de aprendizagem aqui construído foi inspirado no experimento de Piaget e Inhelder, porém, desenvolvido com o objetivo de intervir nos processos de ensino e aprendizagem, oferecendo subsídios ao estudante para chegar ao conhecimento. 
VII Congresso Brasileiro de Informática na Educação (CBIE 2018)

Anais do XXIX Simpósio Brasileiro de Informática na Educação (SBIE 2018)

Para o desenvolvimento do objeto de aprendizagem foi utilizado a plataforma App Inventor. A plataforma, mantida pelo Massachusetts Institute of Technology, é um ambiente de programação visual que permite que pessoas, mesmo que não possuem conhecimento tecnológico aprofundado, criem aplicativos totalmente funcionais para dispositivos móveis (MIT, 2018). Com isso, o estudo pretende explorar aspectos da interface da plataforma, como forma de incentivo para professores e tutores na criação dos seus próprios aplicativos para o uso pedagógico na sala de aula.

\section{App Inventor: Ambiente de Programação Visual para dispositivos móveis}

O MIT App Inventor ${ }^{1}$ é uma ferramenta de programação, disponibilizada em uma plataforma web que permite a construção de aplicativos (app) para ambiente Android, utilizando uma Visual Programming Language (VLP). As VLP permitem que a construção de algoritmo seja realizada por meio de interação com elementos visuais, esses elementos podem ser blocos que representam estruturas algorítmicas, tais como "for", "while" e "if-then-else" e variáveis (Ribeiro, Brandão, \& Brandão, 2012). Assim, esse tipo de linguagem vem ganhando popularidade por permitir o uso fácil de elementos de programação por meio de ações como clicar e arrastar.

Com base nesse paradigma, o MIT App Inventor busca democratizar o desenvolvimento de software, capacitando qualquer pessoa para passar de consumidor de tecnologia para a desenvolvedor de tecnologia (Massachusetts Institute of Technology, 2018). A construção do aplicativo é totalmente online. Apenas é necessário a instalação do aplicativo MIT App Inventor Companion em um dispositivo móvel para realizar testes no seu aplicativo. Aqueles que não possuírem um dispositivo móvel Android precisará instalar um emulador em seu computador para isso.

O ambiente de programação App Inventor é composto, basicamente, por duas abas denominadas Designer e Blocks. Na aba Designer é criada a interface do aplicativo. Aqui, elementos como botões, legendas, imagens, som, ou mesmo componentes mais complexos, como banco de dados estão disponíveis na área Palette e podem ser arrastados para a área principal do aplicativo, chamada Viewer. A programação desses componentes, ou seja, o comportamento desses elementos, é realizada na aba Blocks, por meio de blocos lógicos que podem ser arrastados para a área principal, formando o algoritmo do aplicativo.

\section{Materiais e Métodos}

Para a construção do objeto educacional foi seguido um processo mínimo de desenvolvimento de software, com o objetivo de delinear um conjunto de atividades organizadas para definir, desenvolver, testar e manter os aplicativos desenvolvidos. Por mais simples que seja o desenvolvimento em uma plataforma como o App Inventor, é recomendável a definição de etapas para esse processo, permitindo maior clareza no delineamento do objetivo de aprendizagem, bem como as estratégias pedagógicos que se pretende seguir.

Diante disso, para esse projeto seguiu-se uma sequência de quatro etapas: Requisitos, Desenho, Desenvolvimento e Teste. No levantamento dos requisitos foi estudado o experimento desenvolvido por Piaget e Inhelder e realizado entrevista com

\footnotetext{
${ }^{1} \mathrm{O}$ ambiente de criação do MIT App Inventor está acessível no link http://ai2.appinventor.mit.edu/.
} 
VII Congresso Brasileiro de Informática na Educação (CBIE 2018)

Anais do XXIX Simpósio Brasileiro de Informática na Educação (SBIE 2018)

uma professora de ciências, que trabalha esses conceitos com turmas do $9^{\circ}$ ano do ensino fundamental.

Em sequência, na fase de desenho realizou-se a modelagem, delineando a interface do aplicativo. Nesta fase deve-se descrever como o objetivo definido na fase anterior será alcançado. Diante disso, o aplicativo foi desenhado em forma de uma Sequência Didática a fim de oferecer ao estudante diferentes momentos de aprendizagem. Assim, o aplicativo foi pensado em quatro etapas, iniciando com o experimento de Piaget e Inhelder, com o objetivo de aguçar a curiosidade dos alunos sobre o tema, e então, ao avançar para as próximas telas, os conceitos seriam introduzidos de forma progressiva. A Tabela 1 apresenta as definições dos principais objetivos de cada etapa da sequência didática e quais os principais componentes do App Inventor necessários para atender os requisitos.

Tabela 1. Objetivos e principais componentes para cada etapa do aplicativo

\begin{tabular}{|c|c|c|c|c|}
\hline & $1^{0}$ etapa (tela) & $2^{\circ}$ etapa (tela) & $3^{\circ}$ etapa (tela) & $4^{\circ}$ etapa (tela) \\
\hline Objetivo & $\begin{array}{l}\text { Experimentação no } \\
\text { tanque de água. }\end{array}$ & $\begin{array}{l}\text { Abordar por que } \\
\text { um barco não } \\
\text { afunda na água. }\end{array}$ & $\begin{array}{l}\text { Oportunizar a } \\
\text { experimentação } \\
\text { novamente, com } \\
\text { objetos diferentes. }\end{array}$ & $\begin{array}{l}\text { Fechamento com a } \\
\text { definição dos } \\
\text { conceitos. E uma } \\
\text { atividade final. }\end{array}$ \\
\hline $\begin{array}{l}\text { Principais } \\
\text { componentes } \\
\text { do App } \\
\text { Inventor }\end{array}$ & $\begin{array}{l}\text { Canvas e } \\
\text { ImageSprite para a } \\
\text { criação da animação } \\
\text { e TinyWebDB para } \\
\text { armazenar as } \\
\text { respostas dos } \\
\text { estudantes. }\end{array}$ & $\begin{array}{l}\text { Image e } \\
\text { ActivityStarter } \\
\text { para apresentar } \\
\text { um vídeo. }\end{array}$ & $\begin{array}{l}\text { Canvas e } \\
\text { ImageSprite para a } \\
\text { criação da animação. }\end{array}$ & $\begin{array}{l}\text { Image e } \\
\text { ActivityStarter } \\
\text { para apresentar } \\
\text { um vídeo e } \\
\text { TinyWebDB para } \\
\text { armazenar os } \\
\text { relatórios finais } \\
\text { dos estudantes. }\end{array}$ \\
\hline
\end{tabular}

Fonte: Elaborada pelos autores

Por fim, passou-se para as fases de desenvolvimento e testes. Os testes foram realizados com o objetivo de garantir que o aplicativo criado correspondesse ao que foi descrito nas fases anteriores, com isso, além dos testes regulares de implementação, o mesmo foi testado pela professora de Ciências. Todos os testes ocorreram em dispositivos móveis com sistema operacional Android com versão superior a 5.0.

\section{Desenvolvimento do Objeto Educacional}

O objeto de aprendizagem denominado "Flutua ou Afunda?" (Figura 1) explora conceitos como Densidade e Empuxo, para isso utiliza de experimentação, vídeos, questionamentos e uma atividade final, da qual os alunos precisam escrever um pequeno relatório sobre o que aprendeu. A primeira tela contém diferentes objetos dos quais o aluno deve decidir se afunda ou flutua na água, ao fazer sua escolha, o aluno precisa informar quais as razões da sua classificação.

Essa experimentação no tanque pretende proporcionar um momento de reflexão sobre suas concepções em relação ao tema. As reflexões podem levar a respostas, como: "O objeto afunda por ser pesado" ou então "Ele flutua por ser pequeno", porém, por meio da experimentação ele pode perceber que, por exemplo, uma moeda "pequena" e "leve" não irá flutuar. Aqui pretende desestabilizar concepções que até então estavam estáveis, para que um novo arranjo seja construído, gerando assim, avanços na compreensão conceitual dos alunos. 
VII Congresso Brasileiro de Informática na Educação (CBIE 2018)

Anais do XXIX Simpósio Brasileiro de Informática na Educação (SBIE 2018)

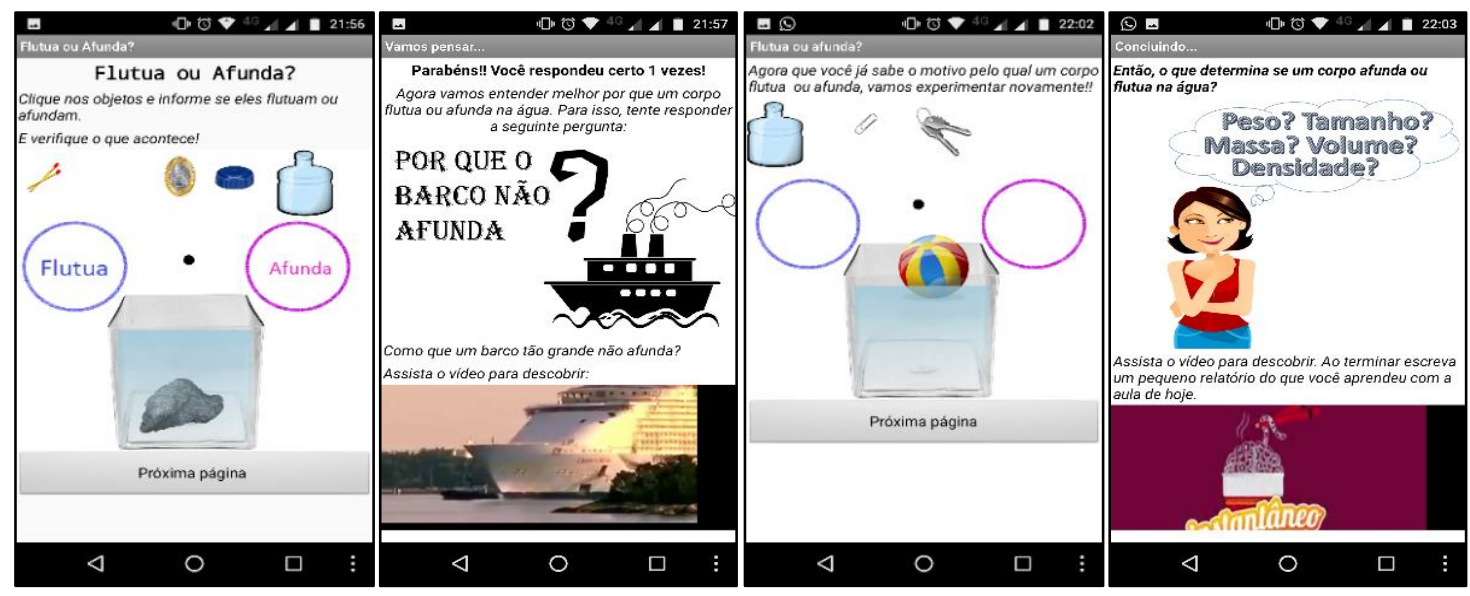

Figura 1 - Objeto de Aprendizagem Flutua ou Afunda?

Depois que o aluno termina sua experiência, ele é levado a uma nova tela. Nesse momento, é introduzido os conceitos de densidade e empuxo, por meio do questionamento "Por que o barco não afunda?", e para responder, um vídeo é apresentado. Com ideias iniciais sobre os conceitos, o aluno é redirecionado a uma nova tela, da qual ele é convidado a realizar novamente o experimento no tanque com novos objetos. Por fim, na última tela o assunto é aprofundado com novo vídeo e o aluno deve escrever um pequeno relatório sobre o que aprendeu. Os vídeos são inseridos como links para o Youtube ${ }^{2}$.

As entradas do usuário (a reflexão sobre o motivo do objeto flutuar ou afundar e o relatório final) são armazenadas em um banco de dados. O banco de dados utilizado é próprio do MIT App Inventor, o TinyWebDB. Para resgatar essas informações, para serem usadas pelo professor, foi desenvolvido um segundo app que permite a visualização dos relatórios.

\section{Conclusões}

Este trabalho apresenta uma proposta de um objeto digital de aprendizagem, desenvolvido por meio da plataforma MIT App Inventor. Com isso teve como objetivo explorar as possibilidades da plataforma e verificar sua potencialidade para professores criarem seus próprios aplicativos para o uso pedagógico. Por meio dos estudos, pode-se perceber que a ferramenta tem potencialidade para o desenvolvimento de apps móveis até mesmo complexos, com a possibilidade de utilizar de recursos como sensores e banco de dados.

Acredita-se que a ferramenta é adequada para o desenvolvimento de apps simples por professores, mesmo para aqueles que não possuem conhecimentos profundos em programação. Uma pequena introdução a programação já pode ser suficiente para que estes possam desenvolverem seus próprios aplicativos. Entretanto, para utilizar de recursos mais complexos, acredita-se que deverá empregar um tempo maior para a compreensão e aplicação desses recursos.

Outro ponto positivo da plataforma é a oportunidade de compartilhamento e reaproveitamento dos aplicativos, que podem representar uma grande oportunidade para os professores. Para trabalhos futuros objetiva-se realizar a validação da adequabilidade

\footnotetext{
${ }^{2}$ https://www.youtube.com/watch?v=Midi7z5n1Ro https://youtu.be/Vls9E6TUB-w
} 
VII Congresso Brasileiro de Informática na Educação (CBIE 2018)

Anais do XXIX Simpósio Brasileiro de Informática na Educação (SBIE 2018)

do objeto de aprendizagem com turmas de $9^{\circ}$ ano do ensino fundamental. Ainda, pretende-se realizar capacitação docente para o uso do ambiente MIT App Inventor.

\section{References}

Nogueira, C. M. I., \& Rezende, V. (2014). A teoria dos campos conceituais no ensino de números irracionais: implicações da teoria piagetiana no ensino de matemática. Schème-Revista Eletrônica de Psicologia e Epistemologia Genéticas, 6(1), 41-63.

Piaget, J., \& Inhelder, B. (1976). Da lógica da criança à lógica do adolescente. São Paulo: Pioneira, 1955.

Ribeiro, R. d. S., Brandão, L. d. O., \& Brandão, A. A. (2012). Uma visão do cenário Nacional do Ensino de Algoritmos e Programação: uma proposta baseada no Paradigma de Programação Visual. Artigo apresentado no Simpósio Brasileiro de Informática na Educação-SBIE.

Massachusetts Institute of Technology. (2018). MIT App Inventor, from http://appinventor.mit.edu/explore/about-us.html 